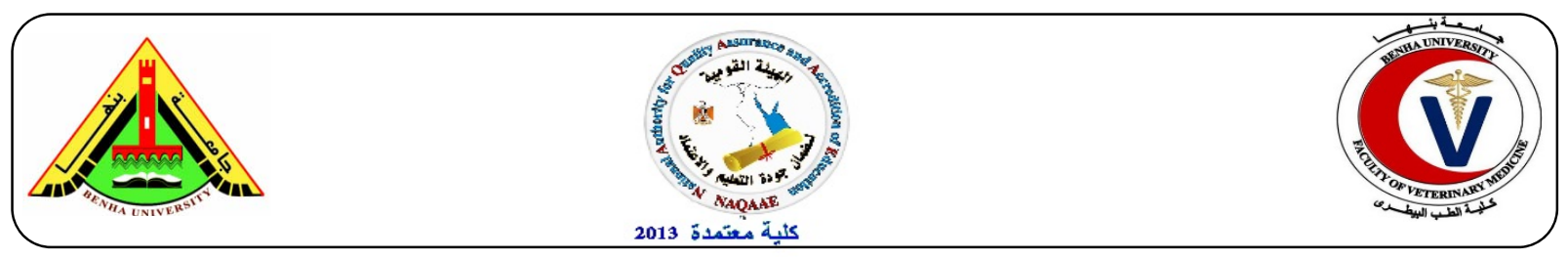

\title{
Synergistic antimicrobial activity of black pepper extract with some antibiotics combination on Escherichia coli isolated from chickens
}

\author{
Ashraf A. Abd EL-Tawab'., Ahmed M. A. Ammar²,, Ahmed M. A. Hamouda ${ }^{3}$., Fatma I. \\ A. El-Hofy ${ }^{1}$ and Abdelrahman A. A. Elgamal \\ ${ }^{1}$ Department of Bacteriology, Immunology and Mycology Fac. Vet. Med Benha University, Egypt. \\ ${ }^{2}$ Department of Microbiology Fac. Vet. Med Zagazig University, Egypt. \\ ${ }^{3}$ Department of Microbiology Animal Health Research institute Egypt.
}

\section{A B S T R A C T}

Antimicrobial activity of methanol piper nigrum extract in combination with some antibiotics was investigated against Escherichia coli isolated from chicken samples. The in-vitro antimicrobial sensitivity pattern of these isolates was done and the intermediate isolates were checked for combination with methanol piper nigrum extract after detecting their antimicrobial activities against these isolates by both disc diffusion test and MIC and the obtained data showed that antimicrobial activities of amoxicillin, doxycycline, gentamicin, erythromycin and cefotaxime were enhanced in combination with methanol piper nigrum extract. The obtained data showed that enhancement by both disc diffusion test and MIC for methanol piper nigrum extract and each of the mentioned antibiotics in decimal assay of additivity ratio was ( 0.5 for amoxicillin, cefotaxime and 0.5 for extract and 0.4 for doxycycline, gentamicin, and erythromycin and 0.6 for extract) against $E$. coli isolates.

Keywords: antimicrobial combination, black pepper extract, Escherichia coli, antibiotics, synergism.

(http://www.bvmj.bu.edu.eg)

(BVMJ-32(1): 1 -6, 2017)

\section{INTRODUCTION}

New antibiotics were produced by pharmacological industries in the last three decades. However, these antibiotics were failed to discourage the growth of many bacteria that have genetic ability to transmit and acquire resistance to drugs. Thus, infections with these bacteria are associated with high morbidity and mortality especially with immune compromised patients in addition, many researchers have established the side effect of overuse and misuse of antibiotics which can harm vital organs like liver, kidneys and some cells such as the pancreas and spleen as well as their impact on the immune system. The known success of traditional medicine has guided the search for new chemotherapeutic alternatives to eliminate the infections caused by drug-resistant microbes and to reduce the harm caused by antibiotic. Medicinal plants are rich in a wide variety of secondary metabolites, such as tannins, terpenoids, alkaloids, flavonoids, phenols and quinines which have been used worldwide in traditional medicine to treat several diseases and infections. Many studies all over the world have been showed that these plants and their extracts have multi-antimicrobial properties .Although 25 to $50 \%$ of the current pharmaceuticals are derived from plants, none is used as antimicrobials. Evaluation of antimicrobial agents and selection of appropriate therapy have became difficult due to the presence of similar agents within the same therapeutic class (White et al., 1993). Thus, it is extremely important to find new antimicrobial agents or new ways that are effective for the treatment of infectious diseases caused by drugresistant bacteria (Taylor et al., 2002). Few studies have found that the efficacy of antimicrobial agents can be improved by combining them with plant extracts against different multidrug-resistant pathogens (Horiuchi et al., 2007; Ibezim et al., 2006). There is a crucial and urgent need to develop new classes of antibiotics or to revitalize existing antibiotics (Tan et al., 2000). Biological effects of these plants on prokaryotic and eukaryotic organisms have been discussed by few studies. However, plants have an almost infinite ability to synthesize compounds that have diverse bioactive properties that cannot be synthesized. Moreover, a large number of plant species have not been 
studied for potential medicinal value or described (Ababutain, 2011).

Due to the increase of resistance to antibiotics, there is a pressing need to develop new and innovative antimicrobial agents. Among the potential sources of new agents, plants have long been investigated because, they contain many bioactive compounds that can be of interest in therapeutic. Because of their low toxicity, there is a long tradition of using dietary plants in the treatment of infectious disease in Cameroonian folk medicine (Djeussi et al., 2013). Antimicrobial combinations may be resulted in synergistic, antagonistic, indifferent or additive action, the invitro tests which may be performed included disc diffusion or breakpoint sensitivity testing and determination of minimum inhibitory concentration (MIC) and minimum bactericidal concentration MBC (Makie and McCartney, 1996). Combination therapies have a real and broad potential to address antibiotic resistance and antibiotic use (Cottarel and Wierzbowski, 2007). In this respect Chaudhry and Tariq (2006) studied antibacterial potential of aqueous decoction of black pepper (Piper nigrum L.), bay leaf (Laurus nobilis L.), aniseed (Pimpinella anisum L.), and coriander (Coriandum sativum L.) against 176 bacterial isolates belonging to 12 different genera of bacterial population isolated from oral cavity of 200 individuals. The disc diffusion technique was employed. Overall aqueous decoction of black pepper was the most bacterial-toxic exhibited $75 \%$ antibacterial activity as compared to aqueous decoction of bay leaf $(53.4 \%)$ and aqueous decoction of aniseed (18.1\%), at the concentration of $10 \mathrm{ml} /$ disc. The aqueous decoction of coriander did not show any antibacterial effect against tested bacterial isolates. So the aim of this study is synergistic antimicrobial combination of Black pepper extract with some antibiotics on E. coli strains isolated from chicken.

\section{MATERIAL AND METHODS}

\subsection{Samples collection:}

A total of 150 samples were aseptically collected from visceral organs (liver, gall bladder, spleen, kidney, cecum, heart and lung) of clinically diseased and dead chickens of different ages reared in farms located in Sharkia and Dakahlia governorates in period between 2014 till 2015 for isolation and identification of E.coli and to study the antimicrobial interaction with extract against the isolated E.coli.

\subsection{Bacteriological examination:}

\subsubsection{Isolation of E. coli}

Firstly, chickens were scarified, dipped in phenol $5 \%$ solution, opened aseptically for bacteriological examination, the macroscopic lesions were sterilized using preheated scalpel. Then separate loopfuls were taken from heart, liver, gall bladder, spleen, heart \& lung (Siam, 1998). Each separate loopful was directly inoculated into separate nutrient broth tubes, and then sub cultured into MacConkey's broth and MacConkey's agar. The inoculated broth and the streaked agar media were incubated at $37{ }^{\circ} \mathrm{C}$ for $24-48$ hours pure colonies were picked up and preserved onto soft agar for further biochemical and serological identification according to Holt et al. (1999).

\subsubsection{Microscopic examination of suspected isolates:}

Modified Gram's stain was used as described by Cruickshank et al. (1975).

\subsubsection{Biochemical identification of the isolates:}

The methods of biochemical tests used for identification of $E$. coli were carried out according to the schemes described by Cruickshank et al. (1975) and Holt Holt et al. (1999).

\subsubsection{Serological identification of isolates}

Sero diagnosis of E. coli: The isolates were serologically identified according to Kok et al. (1996) by using rapid diagnostic E. coli antisera sets (Denka Seiken Co., Japan) for diagnosis of the Enteropathogenic types.

\subsection{Antimicrobial susceptibility testing}

Antimicrobial susceptibility test for all isolates was done according to description of Smith et al. (1997)

\subsection{Preparation of methanol plant extract:}

The collected plant (Black pepper) was cleaned out of other contaminated plants and the fresh plant was collected and air dried away from sun light then the dried plants were crushed to powder using grinder. The powdered plant stored in tightly closed sterile containers until use (Sooad et al., 2012).

\subsubsection{Preparation of plant extract.}

Ten grams of powdered samples was dissolved in $100 \mathrm{ml}$ of methanol in conical flask, plugged with cotton wool and then kept in rotatory shaker at 190$220 \mathrm{rpm}$ for $24 \mathrm{hr}$. The extract was then filtered using conical flask with side arm, a filter funnel size (size 2) and a $90 \mathrm{~mm}$ diameter filter paper. Filtered extract was then poured in weighed $500 \mathrm{ml}$ 
round bottom flask Solvent and evaporated with rotatory evaporator. Temperature of the water bath in the rotatory evaporator was set at $40 \mathrm{c}$.This temperature was used because the evaporation under reduced pressure makes it possible to evaporate at much lower temperature . Finally the extracts were preserved in sterilized dishes at refrigerator and to prevent from the light effect, they were wrapped with aluminum covers (Sooad et al., 2012).

\subsubsection{Preparation and dilution of stock solution}

Two hundred mg of the dry plant residue were provided and solved in 5\% dimethyl sulfoxide (DMSO) in $1 \mathrm{ml}$ sterile distilled water (stock solution). Extraction with concentration of 100, 50, $25,12.5,6.25,3.15,1.56,0.78 \mathrm{mg} / \mathrm{ml}$ distilled water were prepared (Sooad et al. 2012).

\subsubsection{Preparation of discs' susceptibility testing containing Plant extract.}

This was carried out using the modified method of Bauer et al. (1966). Plain discs were sterilized by autoclaving at $121^{\circ} \mathrm{C}$ for $15 \mathrm{~min}$. Cool, flamed forceps were used to firmly apply discs, within 15 min of plate inoculation, to avoid decreased zone diameters. Different concentration (100, 50, 25, 12, 5 and $6,25 \mathrm{mg} / \mathrm{ml}$ ) of plant extract were kept on Plain discs using micro titer pipette with sterile tips.

\subsubsection{Antimicrobial susceptibility testing of plant extraction.}

\subsubsection{Detection of MIC of each drug and plant extraction.}

Minimum inhibitory concentration for each selected antibiotic and plant extract was done according to description of Smith et al. (1997).

\subsection{Decimal Assay for additivity of drugs permits delineation of synergy and antagonism ((Chirstine et al., 1993 ).}

Decimal assay for additivity Disk diffusion assays were performed initially with each antibiotic alone over a range of drug masses in order to derive a standard dose-response curve by linear regression analysis. For each antibiotic, there is a linear relationship between the $\log 10$ of the drug mass (in micrograms) on the disk and the diameter of the zone of inhibition (in millimeters) produced. Once a standard curve for each drug alone had been derived, a target zone for each combination to be tested was selected. This target was selected to represent a zone in the midrange of the standard curve for each drug so that increases or decreases in the zone size resulting from drug interactions could be reliably detected. Once a target zone size was selected for a particular combination, the mass of each drug alone (in micrograms) required in order to produce this zone was calculated from the formula for the standard dose response curve. This mass was defined as the biologic equivalence factor (BEF), since it represented the mass of each of the two drugs that would produce the same zone size. Once the BEF had been calculated, a series of 11 decimal mixtures of the two drugs to be examined in combination was prepared. This series represented all possible mixtures of the two drugs that, when combined in 10 parts, added up to one BEF. Thus, if no positive or negative interaction between the drugs occurred, each mixture should have generated the target zone size. Since there are inherent errors in any standard curve and in preparation of the decimal mixtures, controls for these potential errors consisted of each drug added to itself in a similar series of decimal mixtures. The results generated by these 11 single-drug decimal mixtures represented the true additive response. Therefore, results obtained with combination decimal mixtures had to lie outside the range of those obtained with the single-drug decimal mixtures in order to be considered indicative of a positive or negative interaction. Data were also analyzed statistically (Stat View II, Abacus Concepts, Berkeley and Calif.). The mean zone size (k drug) was calculated from the data obtained with the 11 single-drug decimal mixtures, and $95 \%$ confidence intervals $(\mathrm{t}$ distribution) were determined. For the combination of decimal mixtures, the mean zone size (x comb) was calculated by using data obtained with mixtures 1 through 9 only, since mixtures 0 and 10 represented each drug alone. Ninety-five percent confidence intervals ( $t$ distribution) were calculated for this mean as well. Results obtained with the combination were considered indicative of synergism if X comb was larger than -drug A and X Drug B and the 95\% confidence intervals for $\mathrm{X}$ comb did not overlap those for X drug A or X drug B. Results were considered indicative of antagonism if $\mathrm{X}$ comb was smaller than-drug A and X drug B and the 95\% confidence intervals did not overlap. All other results were considered additive.

\section{RESULTS}

A total of 150 samples were aseptically collected from visceral organs 
Abd EL-Tawab et al. (2017). BVMJ-32(1): 1 -6

Table (1): Antimicrobial activities of methanol black pepper (piper nigrum) extract in combination with antimicrobial drugs on selected E.coli isolates.

\begin{tabular}{|c|c|c|c|c|c|c|c|c|c|c|c|}
\hline \multirow{3}{*}{$\begin{array}{l}\text { M.O } \\
\text { E. coli } \\
\text { E3 }\end{array}$} & \multicolumn{4}{|c|}{ Zone of inhibition $(\mathrm{mm})$} & \multicolumn{4}{|c|}{$\mathrm{MIC} \mu \mathrm{g} / \mathrm{ml}$} & \multicolumn{2}{|c|}{ D.D.A ratio } & \multirow[b]{2}{*}{ REACTION } \\
\hline & $\begin{array}{l}\text { extract } \\
\text { black pepper } \\
(25 \mathrm{mg} / \mathrm{ml})\end{array}$ & \multicolumn{2}{|c|}{ Antibiotic } & \multirow{2}{*}{$\begin{array}{l}\text { Combination } \\
20\end{array}$} & \multicolumn{2}{|c|}{$\begin{array}{l}\text { Extract } \\
\text { Black pepper } \\
(25 \mathrm{mg} / \mathrm{ml})\end{array}$} & \multirow{2}{*}{$\begin{array}{l}\text { Antibiotic } \\
64\end{array}$} & \multirow{2}{*}{$\begin{array}{l}\text { Combination } \\
16\end{array}$} & \multirow{2}{*}{$\frac{\mathrm{AB}}{0.5}$} & \multirow{2}{*}{$\begin{array}{l}\text { Extract } \\
0.5\end{array}$} & \\
\hline & 10 & AML & 15 & & 128 & AML & & & & & ENHANCEMENT \\
\hline E14 & 11 & $\mathrm{CT}$ & 11 & 11 & 128 & $\mathrm{CT}$ & 8 & 8 & - & - & NO \\
\hline E21 & 11 & ENR & 16 & 16 & 256 & ENR & 4 & 4 & - & - & NO \\
\hline E33 & 10 & DO & 12 & 17 & 128 & $\mathrm{DO}$ & 16 & 8 & 0.4 & 0.6 & ENHANCEMENT \\
\hline E40 & 9 & GN & 13 & 20 & 256 & GN & 8 & 2 & 0.4 & 0.6 & ENHANCEMENT \\
\hline E42 & 9 & $\mathrm{E}$ & 14 & 18 & 128 & $\mathrm{E}$ & 16 & 4 & 0.4 & 0.6 & ENHANCEMENT \\
\hline E16 & 8.5 & $\mathrm{~F}$ & 14 & 14 & 256 & $\mathrm{~F}$ & 16 & 16 & - & - & NO \\
\hline E28 & 9 & CTX & 20 & 25 & 128 & CTX & 8 & 4 & 0.5 & 0.5 & ENHANCEMENT \\
\hline E15 & 9 & S & 12 & 12 & 128 & $\mathrm{~S}$ & 16 & 16 & - & - & NO \\
\hline
\end{tabular}

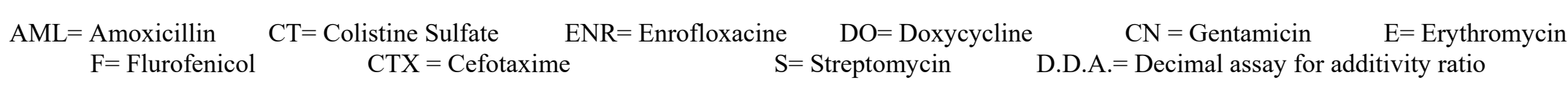


(liver, spleen, kidney, cecum, fecal maters, heart, lung, ovary and swabs from chicken foot and nares) of clinically diseased and dead chickens of different ages reared in farms located in Sharkia and Dakahlia governorates in period between 2014 till 2015 for isolation and identification of $E$. coli and to study the antimicrobial interaction with extract against the isolated $E$. coli. The bacteriological and biochemical examination of these samples revealed the presence of $45 \mathrm{E}$. coli isolates out of 150 specimens with percentages of $30 \%$. The in-vitro antimicrobial sensitivity pattern of these isolates was done and the intermediate isolates were checked for combination with methanol black pepper extract after detecting their antimicrobial activities against these isolates by both disc diffusion test and MIC and the obtained data declared that: Antimicrobial activities of amoxicillin, doxycycline, gentamicin, erythromycin and cefotaxime were enhanced in combination with methanol black pepper extract. The obtained data also showed that enhancement by both disc diffusion test and MIC for methanol black pepper extract and each of mentioned antibiotics in decimal assay of additivity ratio $(0.5$ for amoxicillin, cefotaxime and 0.5 for extract and 0.4 for doxycycline, gentamicin, erythromycin and 0.6 for extract) against $E$. coli isolates (table 1).

\section{DISCUSSION}

The antimicrobials resistance is nowadays considered as a great obstacle for combating infectious diseases, so the aim of this study is to throw spots up on some antimicrobial interactions of some plant extracts against some bacterial isolates to give an idea for practitioners \& specialists of infectious diseases to lay strategic control of the epidemics by using those antimicrobials to save animal wealth.

In this study a total of 150 samples were aseptically collected from visceral organs (liver, spleen, kidney, cecum, fecal maters, heart, lung, ovary and swabs from chicken foot and nares) of clinically diseased and dead chickens of different ages reared in farms located in Sharkia and Dakahlia governorates in period between 2014 till 2015.

Escherichia coli was isolated from chickens in Dakahlia and Sharkia Governorates in Egypt with a percentage of $30 \%$ (45 out of 150 ) The results in this study agreed with those reported by Heba et al. (2012) who isolated E. coli from examined chicken with an incidence $30 \%$ in Alexandria and 23.5\% from examined chicken in Sharkia.
In this study, antimicrobial activity for methanol black pepper extract was detected by both disc diffusion test and MIC against E. coli, salmonella and $S$. aureus isolates and this attitude was supported by Hamdy et al. (2013) who studied the antimicrobial activity and synergistic/antagonistic effect of interactions between antibiotics and some spice essential oils against pathogenic and food spoiler microorganism.

Antimicrobial activities of amoxicillin, ,doxycycline, gentamicin, erythromycin and cefotaxime were enhanced in combination with methanol black pepper extract the obtained data showed that enhancement by both disc diffusion test and MIC for methanol black pepper extract and each of mentioned antibiotics against E.coli isolates, this attitude was supported by Hamdy et al. (2013) who studied the antimicrobial activity and synergistic/antagonistic effect of interactions between antibiotics and some spice essential oils against pathogenic and food spoiler microorganism but no enhancement was observed for enrofloxacin in combination with methanol black pepper against same isolates.

\section{CONCLUSION}

From the results of this study, one can conclude that antimicrobial activities of amoxicillin, doxycycline, gentamicin, erythromycin and cefotaxime were enhanced in combination with methanol black pepper extract. The obtained data showed that enhancement by both disc diffusion test and MIC for methanol black pepper extract and each of mentioned antibiotics against $E$. coli isolates.

\section{REFERENCES}

Ababutain, I.M., 2011. Antimicrobial Activity of Ethanolic Extracts From Some Medicinal Plant. Australian Journal of Basic and Applied Sciences 5, 678-683.

Bauer, A.W., Kirby, W.M.M., Sherris, J.C., Turck, M., 1966. Antibiotic Susceptibility Testing by a Standardized Single Disk Method. Am J Clin Pathol 45, 493-\&.

Chirstine, C., Sanders, W., Eugene, S.J.R., Ellen, S.M., 1993 Decimal Assay for Additivity of Drugs Permits Delineation of Synergy and Antagonism Antimicrobial agents and chemotherapy 260-264.

Cottarel, G., Wierzbowski, J., 2007. Combination drugs, an emerging option for antibacterial therapy. Trends in biotechnology 25, 547-555.

Cruickshank, R., Duguid, J.P., Marmion, B.P., Swain, R.H.A., 1975. Medical Microbiology, 
12th ed. Churchill living stone, Edenburg, London and New York.

Djeussi, D.E., Noumedem, J.A., Seukep, J.A., Fankam, A.G., Voukeng, I.K., Tankeo, S.B., Nkuete, A.H., Kuete, V., 2013. Antibacterial activities of selected edible plants extracts against multidrug-resistant Gram-negative bacteria. BMC complementary and alternative medicine 13, 164.

Hamdy, A.S., Mohamed, B.M.A., Lamyaa, E.E., May, M., A. , 2013. Study on the antimicrobial activity and synergistic/antagonistic effect of interactions between antibiotics and some spice essential oils against pathogenic and food-spoiler microorganisms. Journal of Applied Sciences Research 9, 5076-5085.

Heba, R., Abd El-Aziz, S., Refai, M., 2012. Incidence of E. coli in chickens and ducks in different governorates in Egypt. Conf. of An. Health Res. Inst. Assoc. 1st 420 - 426.

Holt, J.C., Krieg, N.R., Sneath, P.H.A., Staley, J.T., Willians, S.T., 1999. Bergey manual of determinative bacteriology, 9th ed. Williams and Wilkine, A waverly Company, Michigan State University.

Horiuchi, K., Shiota, S., Kuroda, T., Hatano, T., Yoshida, T., Tsuchiya, T., 2007. Potentiation of antimicrobial activity of aminoglycosides by carnosol from Salvia officinalis. Biol Pharm Bull 30, 287-290.

Ibezim, E.C., Esimone, C.O., Nnamani, P.O., Onyishi, I.V., Brown, S.A., Obodo, C.E., 2006. In vitro study of the interaction between some fluoroquinolones and extracts of kola nitida seed. African Journal of Biotechnology 5, 1781-1784.

Kok, T., Worswich, D., Gowans, E., 1996. Some serological techniques for microbial and viral infections. In Practical Medical Microbiology (Collee, J.; Fraser, A.; Marmion, B. and Simmons, A., eds.), 14th ed. Edinburgh, Churchill Livingstone, UK.

Makie, McCartney, 1996. Practical medical microbiology 14th ed. churchet living stone, USA.

Siam, M.A.H. 1998. Colisepticemia in poultryM.V.Sc., Zagazig Univerity, Egypt.

Smith, C.E., Foleno, B.E., Barrett, J.F., Frosco, M.B., 1997. Assessment of the synergistic interactions of levofloxacin and ampicillin against Enterococcus faecium by the checkerboard agar dilution and time-kill methods. Diagn Microbiol Infect Dis 27, 8592.

Sooad, A., Manar, A., Nora, A., Rawan, A., Amal, B., Seema, Z., Ramesa, S.B., 2012. Antibacterial activity and phytochemical screeninigof some medicinal plants commonly used in Saudi Arabia against selected pathogenic microoganisms. Jouranl of King Saud university 25, 115-120.

Tan, Y.T., Tillett, D.J., McKay, I.A., 2000. Molecular strategies for overcoming antibiotic resistance in bacteria. Mol Med Today 6, 309-314.

Taylor, P.W., Stapleton, P.D., Paul Luzio, J., 2002. New ways to treat bacterial infections. Drug Discov Today 7, 1086-1091.

White, R.L., Kays, M.B., Friedrirch, L.V., Del-Ben, V.E., 1993. Impact of different statistical methologies on the evaluation of the in-vitro MICs for bacteroides fragilis of selected cephalosporins and cephamycins. J. Antimcrob. Chemother 31, 57-64. 